\title{
TI.111.1
}

\section{LDAP representations of membership in groups}

- PDF: internet2-mace-dir-ldap-group-membership-200507.pdf

- HTML: internet2-mace-dir-ldap-group-membership-200507.html

\section{More Information}

\begin{tabular}{|l|l|}
\hline Repository ID & TI.111.1 \\
\hline Persistent URL & http://doi.org/10.26869/TI.111.1 \\
\hline Title & LDAP representations of membership in groups \\
\hline Authors & Keith Hazelton \\
\hline Sponsor & MACE \\
\hline Review & \\
\hline Status & Legacy \\
\hline Publish Date & July 5,2005 \\
\hline DOI & $10.26869 /$ TI.111.1 \\
\hline Signature & \\
\hline Deprecated & No \\
\hline Future Review & \\
\hline Supersedes & \\
\hline Format & PDF, HTML \\
\hline Related Docs & \\
\hline Development Location & \\
\hline IP Framework & \\
\hline Subject Tags & middlewarerescue \\
\hline Notes & \\
\hline & \\
\hline
\end{tabular}

